\title{
Conjuntivite granulomatosa atípica causada pela doença da arranhadura do gato - Relato de caso
}

\author{
Cat-scratch disease causing atypical granulomatous conjunctivitis - Case report
}

\author{
Alexandre Hassler Príncipe de Oliveira ${ }^{1}$ \\ Carlos Alberto Pires Pereira ${ }^{2}$ \\ Luciene Barbosa de Sousa ${ }^{3}$ \\ Denise de Freitas ${ }^{4}$
}

\begin{tabular}{|c|}
\hline RESUMO \\
\hline Relatamos caso de paciente do sexo feminino, brasileira, 23 anos, residente \\
na Alemanha, que cursou com quadro de conjuntivite granulomatosa \\
bilateral crônica, sem acometimento ganglionar, nãoresponsiva a tratamento \\
tópico. A pesquisa laboratorial confirmou diagnóstico de conjuntivite por \\
Bartonella henselae. O caso demonstra que a ausência de acometimento \\
ganglionar não exclui o diagnóstico de doença da arranhadura do gato.
\end{tabular}

Descritores: Conjuntivite bacteriana; Bartonella henselae; Doença da arranhadura do gato; Granuloma; Doenças da conjuntiva; Relato de caso

\section{INTRODUÇ̃̃̃O}

A associação entre doença da arranhadura do gato (DAG) e a síndrome óculo-glandular de Parinaud (SOGP) é conhecida desde $1937^{(1-3)}$. O bacilo Gram negativo Bartonella henselae é o agente etiológico mais comumente envolvido. A SOGP é descrita como uma conjuntivite granulomatosa unilateral, acompanhada de enfartamento ganglionar submandibular ou préauricular ipsilateral, supostamente causada pela inoculação direta do olho $^{(4)}$. Outras manifestações da infecção por Bartonella henselae incluem: retinocoroidite, neurorretinite e panuveíte ${ }^{(3)}$. Relatamos um caso atípico de conjuntivite granulomatosa bilateral, sem enfartamento ganglionar, em que se documentou a presença da Bartonella henselae.

\section{RELATO DE CASO}

Paciente de 23 anos, feminina, brasileira, residente na cidade de Kiel na Alemanha nos últimos dois anos, sem antecedentes patológicos. Procurou o ambulatório de córnea do departamento de oftalmologia da Universidade Federal de São Paulo, com história de ter sido tratada de uma conjuntivite durante dois meses sem sucesso. Relatava o uso de colírio de Ofloxacina e Levofloxacina por diversas ocasiões, sem melhora.

Ao exame apresentava acuidade visual igual a 1 e pressão ocular de $12 \mathrm{mmHg}$ em ambos os olhos. Observava-se hiperemia e vasodilatação intensa em conjuntiva bulbar e tarsal, múltiplos nódulos necrosantes em conjuntiva bulbar e infiltrados corneais superficiais em ambos os olhos (Figura 1 e 2). O exame fundoscópico mostrava-se sem alterações em ambos os olhos. Não apresentava gânglios palpáveis. Negava qualquer antecedente ocular ou sistêmico. Após questionamento especifico, relatou contato íntimo com gatos e viagem recente para a floresta na Alemanha. Foi coletado material da conjuntiva para citologia, cultura e pesquisa para Clamídia. Foram solici- 


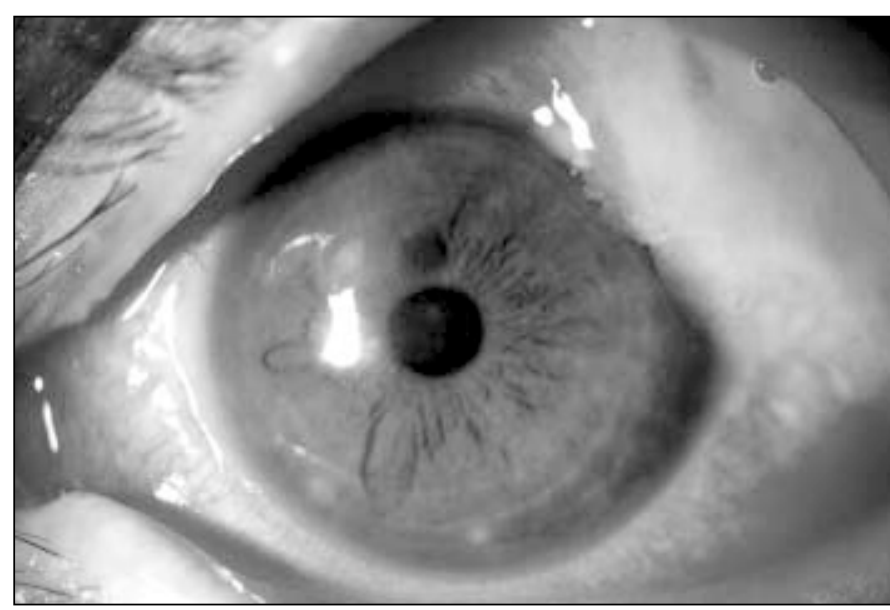

Figura 1 - Olho esquerdo, infiltrado corneal e tumoração conjuntival

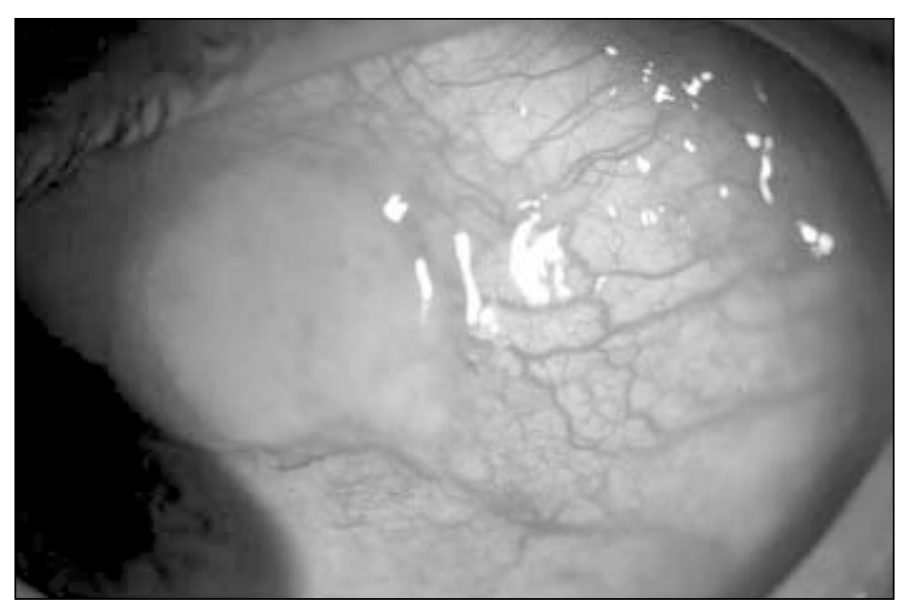

Figura 2 - Olho esquerdo, granuloma na conjuntiva bulbar

tado exames laboratoriais para sífilis, tuberculose, sarcoidose, tularemia, doença da arranhadura do gato, doença de Lyme, esporotricose e AIDS. Raio X de tórax e hemograma completo também fizeram parte da pesquisa. A paciente não permitiu a realização de biópsia da conjuntiva. Baseado no antecedente epidemiológico de DAG foi prescrito Ciprofloxacina $500 \mathrm{mg}$ a cada 12 horas por via oral.

Após uma semana, a paciente retornou com importante melhora dos sinais e sintomas. Os exames laboratoriais revelaram sorológica positiva para Bartonella henselae (controle com B. quintana) com título de IgG superior a $1 / 128$ e IgM superior a $1 / 20$, por imunofluorescência indireta. Os demais exames foram negativos. A ciprofloxacina sistêmica foi mantida por 6 semanas, evoluindo sem seqüelas.

\section{DISCUSSÃO}

Muitos autores recomendam investigar DAG em toda conjuntivite granulomatosa atípica ${ }^{(1)}$. Diversas causas de conjuntivite granulomatosa já foram descritas na literatura ${ }^{(5-6)}$ mas a SOGP, sarcoidose e corpo estranho são as mais comuns. Carithers revisou 1200 casos de DAG, encontrou 48 casos de SOGP e preconizou que linfadenopatia é um pré-requisito para o diagnóstico de $\mathrm{DAG}^{(7)}$. Este relato pode questionar essa afirmação. Apesar da paciente não apresentar gânglios palpáveis, a primeira hipótese diagnóstica foi DAG, devido a exuberante conjuntivite granulomatosa e a história de exposição a gatos. Foi realizada uma investigação laboratorial completa para excluir as causas mais comuns de conjuntivite granulomatosa. A Bartonella henselae é muito difícil de ser isolada em raspados conjuntivais e não cresce em meios de cultura convencionais. Desta forma, a ausência de cultura positiva não permite diagnóstico confiável ${ }^{(4)}$. Uma imunofluorescência indireta positiva, com título de $\operatorname{IgG}$ superior a 64 e com um quadro clínico compatível, confirmam o diagnóstico ${ }^{(4)}$.

No passado, diversos casos de doença ocular causada por Bartonella henselae foram relatados. A maioria foi de SOGP, mas retinocoroidite, neurorretinite, panuveíte e granuloma orbitário já foram reportados ${ }^{(8-9)}$. Na revisão da literatura, não foi encontrado nenhum caso de conjuntivite granulomatosa com ausência de acometimento ganglionar relacionada a DAG. Todos os casos relacionados a DAG eram unilaterais e com envolvimento ganglionar, como mostrado na tabela I. Dos 20 casos pesquisados, 19 tinham gânglios pré-auriculares palpáveis e 1 tinha gânglio parotídeo. Em 1978, foram reportados 7 casos de SOGP. Os pacientes tinham entre 5 e 15 anos de idade, todos tiveram exposição a gatos e envolvimento ganglionar, dois apresentavam nódulos palpebrais e cinco apresentavam nódulos conjuntivais ${ }^{(7)}$. Em 1990, foram reportados dois casos de DAG se apresentando como SOGP. Ambos envolveram a pálpebra causando apenas congestão conjuntival, apresentavam gânglios pré-auriculares e cervicais palpáveis e história de exposição a gatos ${ }^{(10)}$. Observando a tabela, pode-se notar que até 1995 os relatos mostravam apenas teste cutâneo e exame clínico como critérios diagnóstico. Já a partir de 1995, os relatos começaram a apresentar sorologia como método diagnóstico. Hoje a sorologia é considerado um método eficaz e menos invasivo de diagnóstico da DAG, permitindo o diagnóstico de casos atípicos ${ }^{(11)}$.

Ela é especialmente importante nos casos em que não existem lesões acessíveis para biópsia, a qual possibilitaria diagnóstico histológico, ou métodos moleculares de maior especificidade e sensibilidade como o $\mathrm{PCR}^{(12)}$.

A DAG é geralmente autolimitada, e não requer tratamento. Com a exceção dos pacientes imunocomprometidos que podem cursar com quadros atípicos. Apesar de nossa paciente não apresentar sinais de imunocomprometimento, seu quadro atípico e prolongado fez com que nós optássemos por antibioticoterapia ${ }^{(13)}$.

A importância deste caso é ilustrar que, em todos os casos de conjuntivite granulomatosa, mesmo com ausência de acometimento ganglionar, deve-se suspeitar de DAG e o exame sorológico deve ser solicitado. 


\begin{tabular}{|c|c|c|c|c|c|}
\hline Autores/Ano & $\begin{array}{l}\text { Exposição } \\
\text { a gatos }\end{array}$ & $\begin{array}{c}\text { Acometimento } \\
\text { ganglionar }\end{array}$ & $\begin{array}{l}\text { Granuloma } \\
\text { conjuntival }\end{array}$ & $\begin{array}{c}\text { Método } \\
\text { diagnóstico }\end{array}$ & $\begin{array}{c}\text { dade (anos) } \\
\text { /sexo }\end{array}$ \\
\hline Carithers HA, $1978^{14}$ & Sim & Pré-auricular & Sim & Teste cutâneo & $14 / \mathrm{M}$ \\
\hline Carithers HA, 1978 & Sim & Pré-auricular & Sim & Teste cutâneo & $5 / \mathrm{M}$ \\
\hline Carithers HA, 1978 & Sim & Pré-auricular & Sim & Teste cutâneo & $15 / M$ \\
\hline Carithers HA, 1978 & Sim & Pré-auricular & Sim & Teste cutâneo & $7 / \mathrm{F}$ \\
\hline Carithers HA, 1978 & $\operatorname{Sim}$ & Pré-auricular e axilar & Sim & Clínico & $12 / \mathrm{M}$ \\
\hline Carithers HA, 1978 & Sim & Pré-auricular e 2 cervicais & Sim & Teste cutâneo & $13 / \mathrm{F}$ \\
\hline Jawad A ,199010 & $\operatorname{Sim}$ & Parotídeo & Não & Clínico & $50 / M$ \\
\hline Fanous MM, Margo CE $1991^{15}$ & Sim & Pré-auricular & Sim & Clínico & $49 / \mathrm{M}$ \\
\hline Jackson MA $1992^{16}$ & Sim & Pré-auricular & Não & Cultura & $5 / M$ \\
\hline Jackson MA 1992 & Sim & Pré-auricular & Sim & Cultura & $2 / \mathrm{F}$ \\
\hline Kruse LP e cols. $1995^{17}$ & $\operatorname{Sim}$ & Pré-auricular & Sim & Sorologia & $35 / M$ \\
\hline Yamashita CA e cols..$^{18}$ & Sim & Pré-auricular & Sim & Sorologia & 9/M \\
\hline Katia Abarca V e cols.1996 19 & Sim & Pré-auricular & $\mathrm{Sim}$ & Sorologia & $6 / M$ \\
\hline Katia Abarca V e cols. 1996 & Sim & Pré-auricular & Sim & Sorologia & $6 / M$ \\
\hline JC Dondey e cols. $1997^{9}$ & Sim & Pré-auricular e submandibular & Sim & PCR & $51 / \mathrm{F}$ \\
\hline Valle A e cols. $1998^{20}$ & Sim & Pré-auricular & Sim & Clínico & $46 / \mathrm{M}$ \\
\hline Grando D e cols. $1999^{4}$ & Sim & Pré-auricular & Sim & Cultura, sorologia, PCR & $38 / \mathrm{F}$ \\
\hline Massei F e cols. $2000^{11}$ & Sim & Pré-auricular e cervical & Sim & Sorologia & $13 / M$ \\
\hline Starck T e cols. $2002^{21}$ & Sim & Pré-auricular & Sim & Cultura e PCR & $65 / \mathrm{M}$ \\
\hline
\end{tabular}

\section{ABSTRACT}

We report a case of a 23-year-old female patient, Brazilian, resident of Germany, who presented with a bilateral chronic granulomatous conjunctivitis, without lymphoadenopathy and irresponsive to topical treatment. Laboratorial work-up confirmed Bartonella henselae as the etiologic agent. The case shows that the absence of lymphoadenopathy does not exclude the diagnosis of cat-scratch disease.

Keywords: Conjunctivitis, bacterial; Bartonella henselae; Catscratch disease; Granuloma; Conjunctival diseases; Case report

\section{REFERÊNCIAS}

1. Shoham N, Miron D, Raz R, Garzozi HJ. [Familial parinaud oculo-glandular syndrome in cat-scratch disease]. Harefuah 2000;138:1034-6, 1086.

2. Costa PS, Hollanda BV, Assis RV, Costa SM, Valle LM. Parinaud's oculoglandular syndrome associated with paracoccidioidomycosis. Rev Inst Med Trop Sao Paulo 2002;44:49-52.

3. Cunningham ET, Koehler JE. Ocular bartonellosis. Am J Ophthalmol 2000; 130:340-9.
4. Grando D, Sullivan LJ, Flexman JP, Watson MW, Andrew JH. Bartonella henselae associated with Parinaud's oculoglandular syndrome. Clin Infect Dis 1999;28:1156-8.

5. Godfrey DG, Carr JD, Grossniklaus HE. Epibulbar allergic granulomatous nodules in a human immunodeficiency virus-positive patient. Am J Ophthalmol 1998;126:844-6.

6. Barkana Y, Zadok D, Herbert M, Kornberg A, Nemet P. Granulomatous kerato-conjunctivitis as a manifestation of Hodgkin lymphoma. Am J Ophthalmol 2001;131:796-7.

7. Carithers HA. Cat-scratch disease. An overview based on a study of 1,200 patients. Am J Dis Child 1985;139:1124-33.

8. Rothova A, Kerkhoff F, Hooft HJ, Ossewaarde JM. Bartonella serology for patients with intraocular inflammatory disease. Retina 1998;18:348-55.

9. Dondey JC, Sullivan TJ, Robson JM, Gatto J. Application of polymerase chain reaction assay in the diagnosis of orbital granuloma complicating atypical oculoglandular cat scratch disease. Ophthalmology 1997;104:1174-8.

10. Jawad AS, Amen AA. Cat-scratch disease presenting as the oculoglandular syndrome of Parinaud: a report of two cases. Postgrad Med J 1990;66:467-8.

11. Massei F, Messina F, Talini I, Massimetti M, Palla G, Macchia P, et al. Widening of the clinical spectrum of Bartonella henselae infection as recognized through serodiagnostics. Eur J Pediatr 2000;159:416-9.

12. Margolis B, Kuzu I, Herrmann M, Raible MD, Hsi E, Alkan S. Rapid polymerase chain reaction-based confirmation of cat scratch disease and Bartonella henselae infection. Arch Pathol Lab Med 2003;127:706-10.

13. Schutze GE. Diagnosis and treatment of Bartonella henselae infections. Pediatr Infect Dis J 2000;19:1185-7.

\section{Ao enviar um artigo para publicação,} leia ATENTAMENTE as instruções para autores, constante no final de cada fascículo. 